\title{
CALCULATED DRAG OF AN AERIAL REFUELING ASSEMBLY THROUGH AIRPLANE PERFORMANCE ANALYSIS ${ }^{\dagger *}$
}

\author{
Michael Jacob Vachon ${ }^{\ddagger}$ and Ronald J. Ray ${ }^{\S}$ \\ NASA Dryden Flight Research Center \\ Carl Calianno $^{\text {II }}$ \\ NAVAIR
}

\begin{abstract}
The aerodynamic drag of an aerial refueling assembly was calculated during the Automated Aerial Refueling project at the NASA Dryden Flight Research Center. An F/A-18A airplane was specially instrumented to obtain accurate fuel flow measurements and to determine engine thrust. A standard Navy air refueling store with a retractable refueling hose and paradrogue was mounted to the centerline pylon of the F/A-18A airplane. As the paradrogue assembly was deployed and stowed, changes in the calculated thrust of the airplane occurred and were equated to changes in vehicle drag. These drag changes were attributable to the drag of the paradrogue assembly. The drag of the paradrogue assembly was determined to range from 200 to $450 \mathrm{lbf}$ at airspeeds from 170 to 250 KIAS. Analysis of the drag data resulted in a single drag coefficient of 0.0056 for the paradrogue assembly that adequately matched the calculated drag for all flight conditions. The drag relief provided to the tanker airplane when a receiver airplane engaged the paradrogue is also documented from 35 to $270 \mathrm{lbf}$ at the various flight conditions tested. The results support the development of accurate aerodynamic models to be used in refueling simulations and control laws for fully autonomous refueling.
\end{abstract}

\section{NOMENCLATURE}

AAR Automated Aerial Refueling (project)

AFF Autonomous Formation Flight (project)

\$ AIAA Member, Aerospace Engineer

$\S$ Aerospace Engineer

II Aerospace Engineer

${ }^{\dagger}$ Note that use of trade names or names of manufacturers in this document does not constitute an official endorsement of such products or manufacturers, either expressed or implied, by the National Aeronautics and Space Administration.

*This material is declared a work of the U.S. Government and is not subject to copyright protection in the United States.
AIRPAC United States Naval Air Forces, Pacific

ARS air refueling store

ATC autothrottle control

$A_{X_{w}} \quad$ axial acceleration along the $\mathrm{X}$-axis in the wind-axis coordinate system

$C_{D} \quad$ drag coefficient, $C_{D}=2 D /\left(\rho S V^{2}\right)$

$C_{L} \quad$ lift coefficient, $C_{L}=2 L /\left(\rho S V^{2}\right)$

$D \quad$ drag, lbf

$F_{G} \quad$ gross thrust, lbf

$F_{E X} \quad$ excess thrust, lbf

$F_{R A M} \quad$ ram drag, lbf

$F E_{D R A G}$ engine throttle-dependent drag, lbf

gpm gallons per minute

GPS global positioning system

GW gross weight, lbm

IFT in-flight thrust (computer model)

INS inertial navigation system

KIAS knots indicated airspeed

$L \quad$ lift, lbf

lbf pounds force

lbm pounds mass

NASA National Aeronautics and Space Administration

NAVAIR United States Naval Air Systems Command

$N_{Z_{w}} \quad$ Normal acceleration along the Z-axis in the wind-axis coordinate system

$\mathrm{P} / \mathrm{N} \quad$ part number

R degree Rankine

rpm revolutions per minute 


$\begin{array}{ll}S & \text { wing area, } \mathrm{ft}^{2} \\ \text { T/N } & \text { tail number } \\ \text { UAV } & \text { uninhabited aerial vehicle } \\ \text { U.S. } & \text { United States of America } \\ \text { WFT } & \text { fuel flow rate, } \mathrm{lbm} / \mathrm{hr}\end{array}$

\section{Greek}

$\alpha \quad$ airplane angle of attack, deg

$\tau \quad$ engine incidence angle, deg

\section{INTRODUCTION}

From wingwalking stunts to precise automated positioning by satellites, the technology for implementing aerial refueling has vastly evolved since it was conceptualized in 1917 by Alexander de Seversky, ${ }^{1}$ who later patented the idea in 1921. When powered flight was in its infancy, the concept of extending the duration of flights was attractive to many, though seemingly difficult to implement. In 1918, Navy Reserve pilot, Lt. Godfrey Cabot used a grappling hook from his biplane to snag floating gasoline containers from the ocean. The first recorded in-flight refueling was accomplished by Wesley May, who boldly stepped off the wing of his Lincoln Standard biplane and onto the wing skid of a Curtiss JN-4 "Jenny" with a five-gallon can of gasoline on his back as they were flying over Long Beach, California, on November 12, 1921. ${ }^{2}$ As he emptied the can into the Jenny's tank, aerial refueling became a reality.

In 1923, pilots began using a clumsy and dangerous hanging-hose method. The first application of this technique is credited to four crewmen flying two de Havilland DH-4Bs for the U.S. Army Air Service (fig. 1). At an altitude of about $500 \mathrm{ft}$ above Rockwell Field on North Island in San Diego, the airplanes became linked by hose, and one airplane refueled the other on June $27,1923 .^{2}$ Only seventy-five gallons of gasoline were transferred. For the tanker airplane, 1st Lt. Virgil Hine piloted while 1st Lt. Frank W. Seifert occupied the rear cockpit and handled the fueling hose. In the receiver, Capt. Lowell H. Smith was at the controls while 1st Lt. John Paul Richter handled the refueling from the rear cockpit. The refueling system consisted of a fifty-foot length of rubber hose, trailed from the tanker, with a manually operated quick-closing valve at each end.

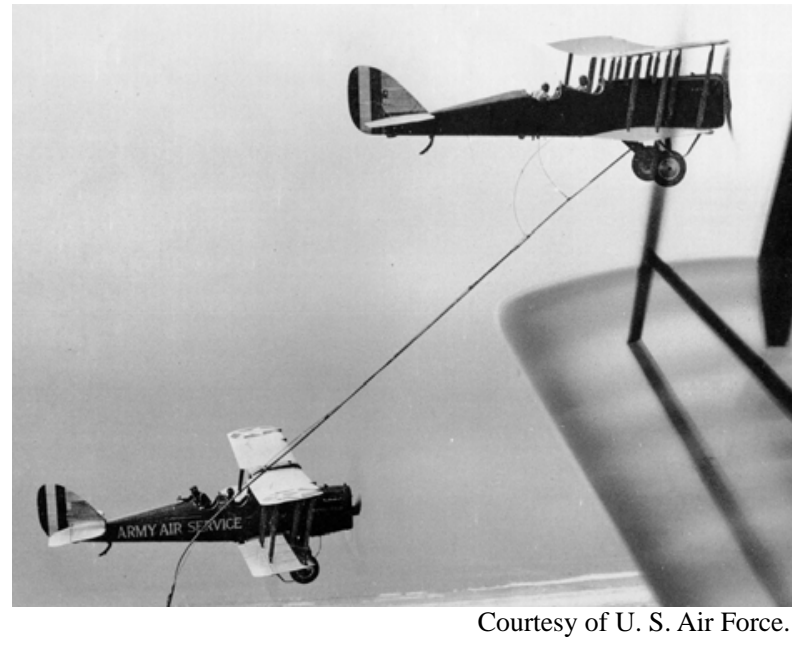

Figure 1. The de Havilland DH-4B receiver grabs a hose dangled by the DH-4B tanker over Rockwell Field.

Modern approaches to aerial refueling have evolved into robust systems that are applied to much higher-performance aircraft, up to 300 knots indicated airspeed (KIAS), and altitudes above $30,000 \mathrm{ft}$, and at higher flowrates - up to 470 gallons per minute (gpm) for the hose-and-drogue method and 1,100 gpm for the boom method. ${ }^{3}$ The hose-and-drogue system uses a paradrogue canopy to provide increased stability (damping) of the airplane-hose-drogue coupled system, a mechanism to deploy the hose from the refueling pod, and a target at which airplanes and helicopters can aim. Because the hose-and-drogue method employed by the U.S. Navy and the boom-receptacle method used by the U.S. Air Force have been an effective and reliable means of refueling aircraft in-flight, the processes have remained remarkably unchanged over the past 50 years. Recent technology advancements have resulted in considering the development of fully autonomous refueling systems using the global positioning system (GPS) and advanced aircraft-to-aircraft communications, guidance, and controls. Such systems are vital to the future of Uninhabited Aerial Vehicles (UAVs) currently being developed and may also be applied to piloted airplanes for aiding fatigued pilots or handling difficult engagements in adverse weather. Important to the development of autonomous refueling control is the accurate modeling of the refueling paradrogue aerodynamics and drag. 
To autonomously refuel, a receiver airplane must be able to safely encounter a tanker airplane without endangering the tanker or its crew. Success depends upon the accurate prediction of the movement of the paradrogue assembly as it is influenced by the forebody of the receiver airplane. One significant contribution to the position of the paradrogue assembly is its aerodynamic drag. It is an ambitious task to be able to optically track or empirically predict the movement of the paradrogue assembly, within the influence of the forebody effects of an approaching airplane.

Giving UAVs the capability to perform autonomous in-flight refueling is of increasing importance to the United States Department of Defense. Broadly, this capability seeks to allow aircraft (either manned or unmanned) to refuel autonomously, i.e., without a pilot in the loop. This would alleviate pilots of a high-workload task and increase the range and effectiveness of UAVs when deployed. Before autonomous in-flight refueling can occur, enabling technologies need to be developed. One such technology is the flight control system, which must enable the airplane to couple with a refueling tanker aircraft and disengage. Several things must be well understood before this can happen, one of which is the flight dynamics of the paradrogue assembly.

The objective of the Automated Aerial Refueling (AAR) project at the NASA Dryden Flight Research Center (Edwards, California) is to develop accurate analytic models, from actual flight test data, that will aid in the development of the design of an autonomous aerial refueling system. The AAR project is attempting to advance technologies critical to the development of UAV AAR simulations, control system design, and sensor and data link requirements.

The air refueling store (ARS) used by the AAR project was originally integrated on S-3 Vikings and most recently on the newer F/A-18E/F Super Hornets during the 1990s. The initial phase of the AAR project demonstrated an acceptable flight envelope for carriage of the ARS and qualitatively assessed the free-stream hose-and-drogue dynamics when installed on the earlier model F/A-18A, which had never been done before. The AAR Phase 0 flight tests consisted of a series of envelope expansion test points to determine the operational envelope of the ARS on an F/A-18A. These flight tests included paradrogue deployments, retractions, and engagements by the receiver airplane at various airspeeds and altitudes. Because the airplane selected to be the tanker for this project was already highly-instrumented for in-flight thrust determination, ${ }^{4}$ an experiment was developed to measure the change in vehicle drag attributable to the deployment of the paradrogue assembly. Phase 1 flight testing involved mapping the effect of the forebody of the receiver airplane on the paradrogue assembly and validating an optical data acquisition system. Data for this paper were derived during these two flight phases. The results of this testing is being applied to developing control laws for an autonomous refueling system.

This paper presents a summary of the vehicle performance impact attributable to the carriage of a hose-and-drogue-type aerial refueling system as obtained by the AAR project during flight tests at the NASA Dryden Flight Research Center. Performance data for the tanker airplane were recorded at a variety of flight conditions: airspeeds from 170 to 250 KIAS and altitudes of 7,500, 21,000 to 25,000, and 29,000 feet. Drag of the paradrogue assembly was computed to range from 200 to $450 \mathrm{lbf}$, depending on flight condition. The flight data was also compared with drag predictions from wind tunnel tests of two paradrogue canopy designs.

\section{AIRPLANE AND ENGINE DESCRIPTION}

The two primary NASA Dryden F/A-18A research airplanes used for the AAR project were originally modified to support the Autonomous Formation Flight (AFF) project. ${ }^{4}$ The F/A-18 airplane is a supersonic, high-performance, multimission fighter powered by two F404-GE-400 turbofan engines each producing $16,000 \mathrm{lbf}$ of thrust in afterburner. The engines are mounted close together in the aft fuselage, effectively providing a single thrust line for the airplane. The F/A-18 airplane has a digital control-by-wire flight control system that provides excellent handling qualities. The airplane has a wingspan of $37 \mathrm{ft} 6$ in., a wing sweep of $20 \mathrm{deg}$ and a wing area of $400 \mathrm{ft}^{2}$. The fuselage is $56 \mathrm{ft}$ long.

The AAR tanker airplane (NASA T/N 847) is a single-seat, F/A-18A airplane formerly flown by the U.S. Navy Blue Angels. It has a gross weight of $36,433 \mathrm{lbm}$ when fully loaded with $10,860 \mathrm{lbm}$ of internal fuel. For the AAR project, this plane was modified with a standard Navy ARS, P/N 31-301-48310-2, acquired on loan from U.S. Naval Air Systems Command/United States Naval Air Forces, Pacific (NAVAIR/AIRPAC) and mounted on a 4-in. adapter at the centerline station (fig. 2). The ARS is a 295-gallon fuel tank powered by a ram air turbine with a retractable hose, paradrogue, and coupling. When used in this paper, the term "paradrogue assembly" refers to the paradrogue assembly of figure 2 , as well as the refueling 

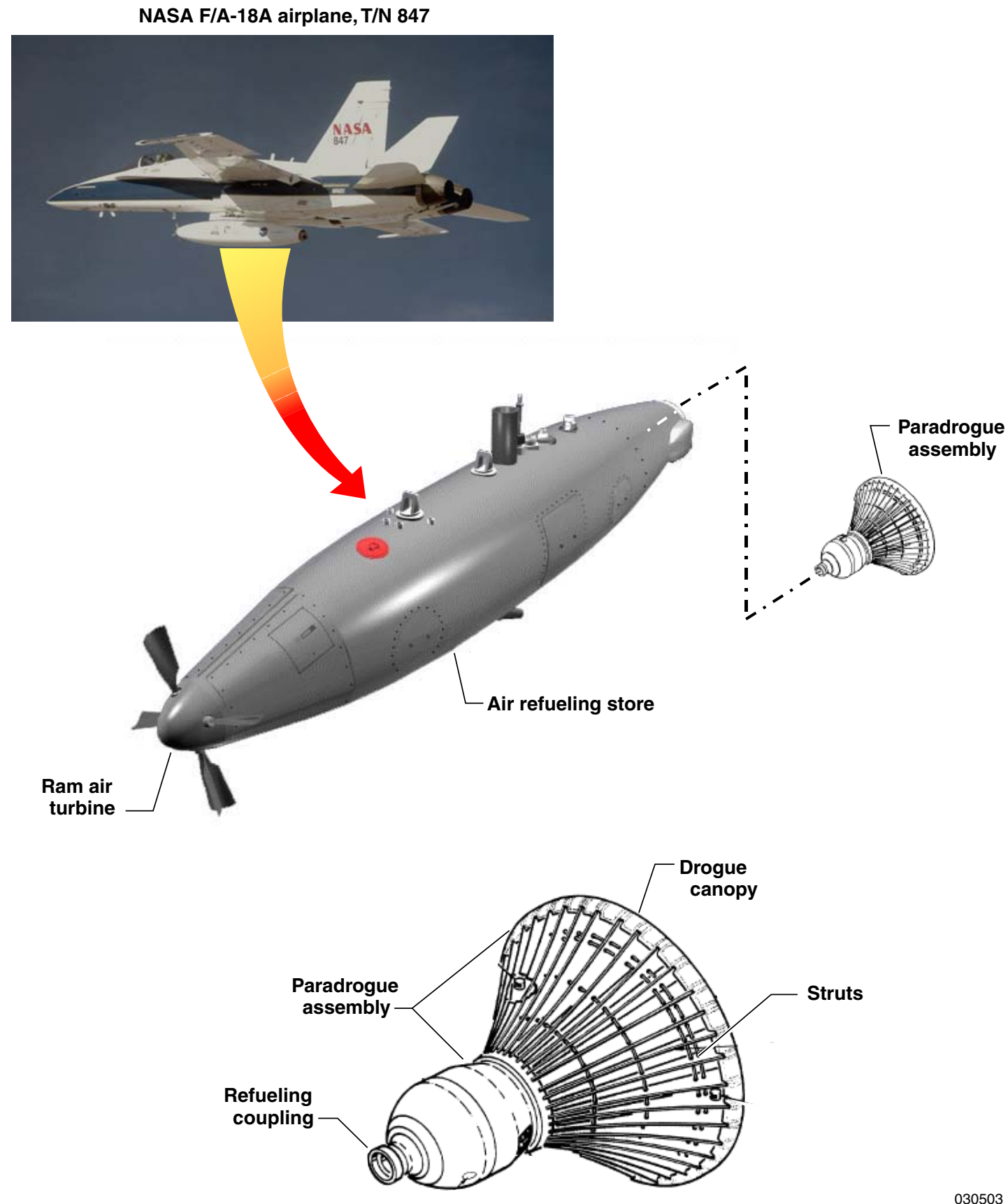

030503

Figure 2. Air refueling store assembly and installation on the F/A-18A airplane. 
hose and coupling. Not included in the airplane gross weight of $36,433 \mathrm{lbm}$, the ARS weighed $2,903 \mathrm{lbm}$ when full and can carry 285 gallons of usable fuel. With the ARS fully fueled, the airplane weighed 40,224 lbm. The total fuel capacity was augmented for Phase 1 flight tests by the addition of two 330-gallon wing tanks mounted at the inboard store locations. With the increased fuel capacity, the F/A-18A airplane became an effective tanker capable of extending the duration of each research mission by refueling the chase airplane(s). Including fully-fueled external tanks (the ARS and two wing tanks) and two outboard wing pylons for mounting aft-facing cameras, the airplane weighed approximately $45,310 \mathrm{lbm}$. The primary receiver airplane (NASA $\mathrm{T} / \mathrm{N} 845)$ is the first full-scale development two-seat TF/A-18A airplane, later designated the first F/A-18B. This airplane has been extensively modified to conduct advanced flight systems research. For the AAR project, it served as a surrogate refueling UAV and applied controlled forebody influences to the paradrogue assembly. Because of the two-seat configuration, this airplane carries about 6 percent less fuel than a standard F/A-18A airplane and has a longer canopy. Carrying a rear seat engineer enhanced safety visibility and assisted the pilot in the conduct of each mission. The airplane weighed $36,021 \mathrm{lbm}$ when fully loaded with $9,926 \mathrm{lbm}$ of fuel. It did not carry any external tanks, but was modified with one pylon on the starboard wing for mounting a forward-facing camera.

\section{INSTRUMENTATION AND DATA ACQUISITION}

Both AAR F/A-18 airplanes were modified with GPS receivers and wireless modems to provide precise relative position information and generate positioning cues for the pilot of the receiver airplane facilitating mapping of the movement of the paradrogue assembly. ${ }^{5}$ A laser-mounted inertial navigation system (INS) was used to obtain tanker airplane accelerations, attitudes, and rates. The standard airplane airdata system was used to obtain Mach number and altitude. The engine manufacturer's aerothermodynamic in-flight thrust (IFT) computer model was used during each flight and postflight to determine thrust values. ${ }^{6}$

The thrust model uses two correlation techniques based upon the gas generator method for determining ideal gross thrust: area-pressure and mass flow-temperature. The mass flow-temperature technique was chosen as the primary method for use in AAR performance calculation because it has proven accuracy on the order of 2 percent for net thrust. ${ }^{7}$ Table 1 shows a summary of the input requirements for the IFT model for both thrust methods. ${ }^{8}$ All of the parameters listed in table 1 were measured or calculated in-flight on the tanker airplane. A 20-probe total pressure rake was installed to determine the average turbine exit pressure.

Table 1. The F404 engine thrust model measurement inputs.

\begin{tabular}{l|l|l|c}
\hline \hline \multicolumn{1}{c|}{ Parameter } & $\begin{array}{c}\text { Area- } \\
\text { pressure }\end{array}$ & $\begin{array}{c}\text { Mass flow- } \\
\text { temperature }\end{array}$ & Range \\
\hline Mach number & secondary & primary & 0 to 2.0 \\
nozzle area & primary & secondary & 220 to $540 \mathrm{in}^{2}$ \\
fan rotor speed & secondary & primary & 0 to $13,270 \mathrm{rpm}$ \\
power lever angle & secondary & primary & 0 to $130 \mathrm{deg}$ \\
ambient pressure & primary & secondary & 0 to $14 \mathrm{lbf} / \mathrm{in}^{2}$ \\
turbine air pressure & primary & secondary & 0 to $60 \mathrm{lbf} / \mathrm{in}^{2}$ \\
fan inlet temperature & secondary & primary & 400 to $800 \mathrm{deg} \mathrm{R}$ \\
primary fuel flow & secondary & primary & 0 to $12,000 \mathrm{lbm} / \mathrm{hr}$ \\
\hline \hline
\end{tabular}


The standard production fuel flow meter did not have the desired frequency response or accuracy to adequately measure fuel flow rate (WFT) for the calculation of engine thrust during quasi-dynamic test points. To obtain the desired response and accuracy, a high-resolution, volumetric fuel flow meter was mounted on each engine of the tanker airplane. During steady throttle positions, the research meter measured fuel flow at an accuracy of 1 percent full-scale and was within 2 percent of the pre-existing production meter, which added confidence to the results. Reference 4 provides more information on the AFF performance instrumentation system.

Video systems were installed on both the tanker and receiver airplanes. Each airplane had two cameras pointed at the area where the paradrogue assembly would transition away from its 'free stream' position under the influence of the forebody of the receiving airplane. The wing-mounted cameras on the tanker airplane were rear-facing and focused on the position behind the airplane where the paradrogue assembly is at quasi-static rest when fully extended. The cameras mounted on the starboard wing of the receiver airplane were forward facing, and the camera views overlap in the region of its refueling probe tip, which was where the paradrogue assembly was anticipated to be during testing.

\section{Data Quality}

There is one drawback to the flight test technique of measuring thrust changes and attributing them to the drag of the paradrogue assembly. The change in paradrogue assembly drag is small enough, compared to the airplane net thrust, that it easily falls within the inaccuracy bounds of the thrust model ( 2 percent of $9000 \mathrm{lbf}$ for two engines at a nominal thrust setting is $180 \mathrm{lbf}$ ). This potential error is virtually eliminated by flying test points back-to-back to eliminate any bias errors such as weight changes, day-to-day atmospheric differences, etc. For each completed test point, data with the paradrogue assembly retracted is compared directly to data with the paradrogue assembly extended as follows:

$$
D_{\text {Drogue }}=\underset{\substack{\text { Airplane } \\ \text { with Drogue } \\ \text { Extended }}}{D_{\text {Airplane }}^{\text {with Drogue }}} \quad-\Delta D_{\text {Trim }}
$$

where $\Delta D_{\text {Trim }}=$ change in drag of horizontal tails, as a result of a change in airplane trim as the angle of attack changes to compensate for paradrogue assembly deployment. A discussion of the trim drag effect is provided in the "Data Uncertainty" section below.

Differences in how far the refueling hose extends on each extension and after each refueling engagement may also affect the drag data. During engagements, the receiver airplane refueling probe connects to and pushes on the paradrogue and hose assembly, causing the hose to partially reel into the ARS when contact is made; and pulls on the hose at full extension when disconnecting. During flight testing, it was noted that the hose does not appear to start and end each engagement at the same position relative to the tanker airplane. Because hose drag is a significant contribution to the overall drag of the refueling system, these changes cannot be wholly ignored, but can be estimated to be small because the difference in hose extension length was estimated to be under 2 feet. Obtaining exact measurements of extended hose length in-flight were impractical at the time, so analyses discussed in this paper assume that the hose length is always fully extended, or 47 feet. This provides us with a worst-case drag estimate for the hose at all steady-state flight conditions, though also introduces a small error in separating the paradrogue drag calculations from the entire assembly, as some of the paradrogue drag may erroneously be attributed to hose drag.

A real-time drag model was implemented in the control room to calculate thrust based upon the IFT model of the manufacturer. Although it is a streamlined version of the more detailed postflight analysis model, the real-time model did provide sufficient information regarding the quality of performance data while the data were being obtained, thus enhancing the efficiency of the data gathering. ${ }^{9}$ Because of this capability, poor quality test points could be immediately repeated if required and dropped from the postflight processing when data quality was not adequate.

A notable change in total airplane drag was observed on the real-time control room displays as the paradrogue assembly was deployed for many test points, similar to the example postflight time history plot of the drag coefficient shown in figure 3 . This drag change can be approximately equated to the total drag of the paradrogue assembly (defined to include the hose, coupling, and paradrogue canopy). 


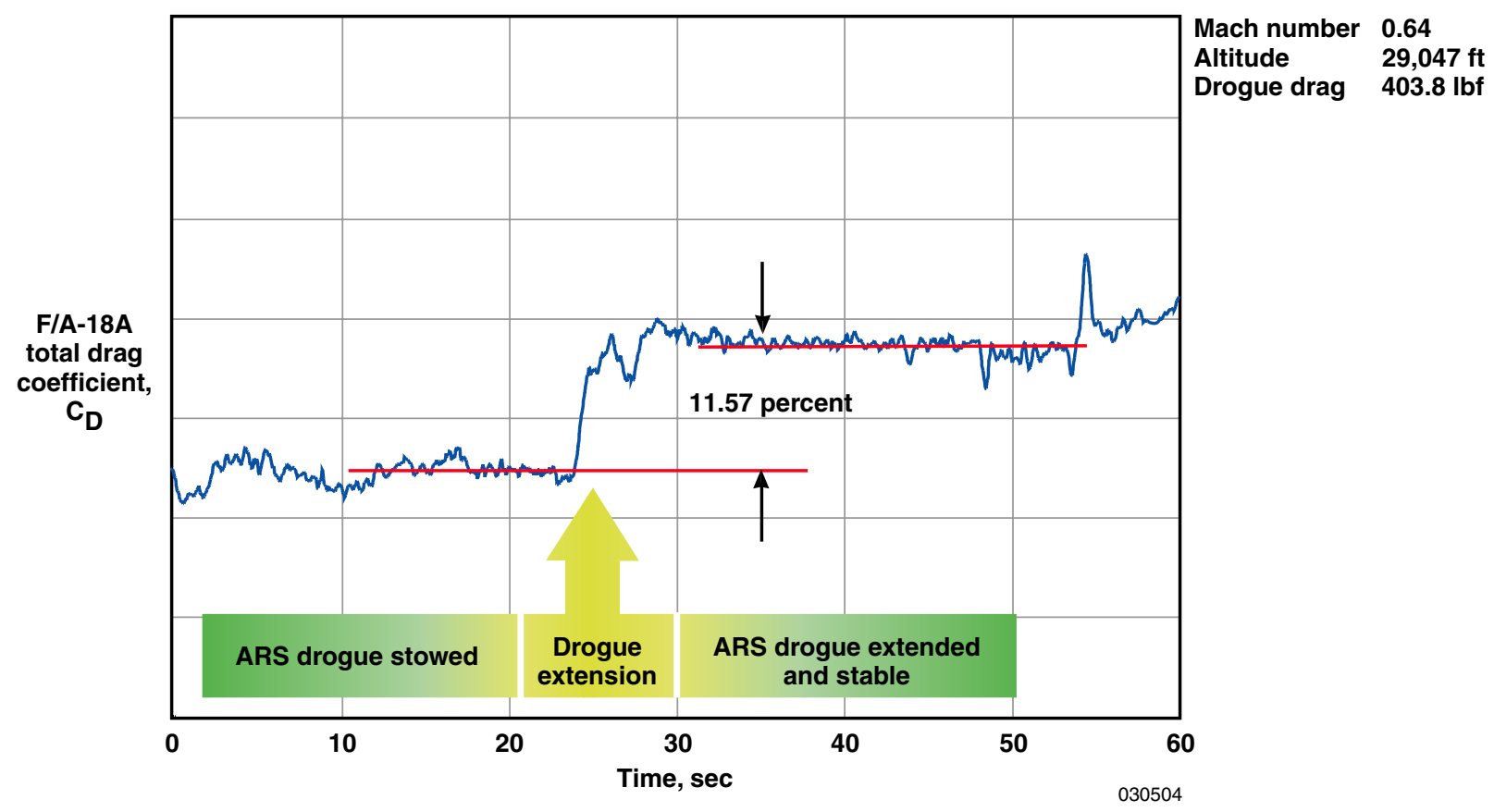

Figure 3. Drag coefficient during a typical test point.

The use of autopilot (barometric altitude hold) and autothrottle control (ATC, or velocity hold) also helped improve data quality. The use of autopilot ensured the airplane maintained constant altitude while the pilot turned his attention to powering up the ARS and deploying the paradrogue assembly. The use of autothrottle ensured that the airplane maintained constant airspeed and any changes made to throttle position during a test point (drogue extension or retraction) were smooth and gradual. Manual throttle use tended to have significantly larger throttle transients applied in step inputs while the pilot tried to maintain conditions, often significantly affecting fuel flow rates. Fortunately, the drag values tend to be insensitive to throttle change unless the amplitude or rate is very high. More information on how data quality affected performance calculations can be found in reference 4 .

Between Phases 0 and 1, the paradrogue canopy was changed out on the ARS. The second canopy was less susceptible to coming unhooked from the paradrogue assembly during missed receiver engagements, when the probe on the receiver airplane would impact the paradrogue assembly. The two canopies were the same design, but had attachment cords of different strengths. This change did not preclude directly comparing data from Phases 0 and 1.

\section{Data Uncertainty}

The uncertainty in the calculated $C_{D}$ of the airplane was estimated to be on the order of three to 5 percent. Because bias effects were minimized by directly comparing the calculated airplane drag while the paradrogue assembly was stowed in the ARS to the drag with the extended paradrogue assembly, the uncertainty of the calculated drag of the paradrogue assembly is better than 3 percent. Several additional factors influenced the final uncertainty of the data. These factors included variations in maneuver technique, air turbulence, stability of the paradrogue assembly position, shape of the paradrogue canopy (sometimes slightly deformed after multiple engagements), and the effect of airplane trim changes.

There are two effects on the data that are attributable to airplane trim changes. Depending on whether a test point was conducted near the beginning or near the end of a flight, the differences in airplane weight, because of fuel burn and transfer of fuel from the external tank(s), changed the location of the airplane center of gravity and consequently the aerodynamic trim characteristics of the airplane. At heavier weight, the airplane is required to generate additional lift, which results in the airplane flying at a higher angle of attack (this will be 
discussed further in the "Results and Discussion" section once the drag polar has been introduced). Additional lift causes an increase in induced drag and total vehicle drag. For two similar flight conditions (altitude and airspeed) in the flight database, the airplane may be at two different trim states or total drag values. By flying test points back-to-back, this error is greatly minimized or eliminated.

The control system of the airplane responds to compensate for the additional drag generated by the extended paradrogue assembly and the moment arm upon which that drag acts. The response is reflected in the trim state of the airplane (angle of attack, control surface deflections, etc.). Because the aircraft changes angle of attack, the horizontal tail must change its trim position to maintain constant altitude. The change in horizontal tail position causes a small change in the trim drag, as shown in equation (1). As the paradrogue assembly was deployed, the average change in deflection of the F/A-18A stabilators was less than three-tenths of one degree (fig. 4). The change in airplane angle of attack was less than two-tenths of one degree for all test points. Tabular data from the F/A-18 simulator provides an estimate of stabilator drag coefficient as a function of airplane angle of attack. Using the curve derived from the simulator table and the change in airplane angle of attack as the paradrogue assembly is deployed or engaged by a receiver, an estimated change in trim drag can be calculated. The worst-case drag increase attributable to this trim drag change is less than two pounds, which is 0.04 percent of the total airplane drag and well within the inaccuracy bounds of the thrust calculation. This trim change is a minor contribution to the overall drag change of the airplane, and if unaccounted for, it can erroneously contribute up to 0.6 percent of the total drag of the paradrogue assembly. To correct this error, the empirical estimates for changes in trim drag were subtracted from the paradrogue assembly drag. Removing this error from the data makes the comparison of flight data with wind tunnel data more valid. All data presented in this paper have been corrected for trim drag in this manner.

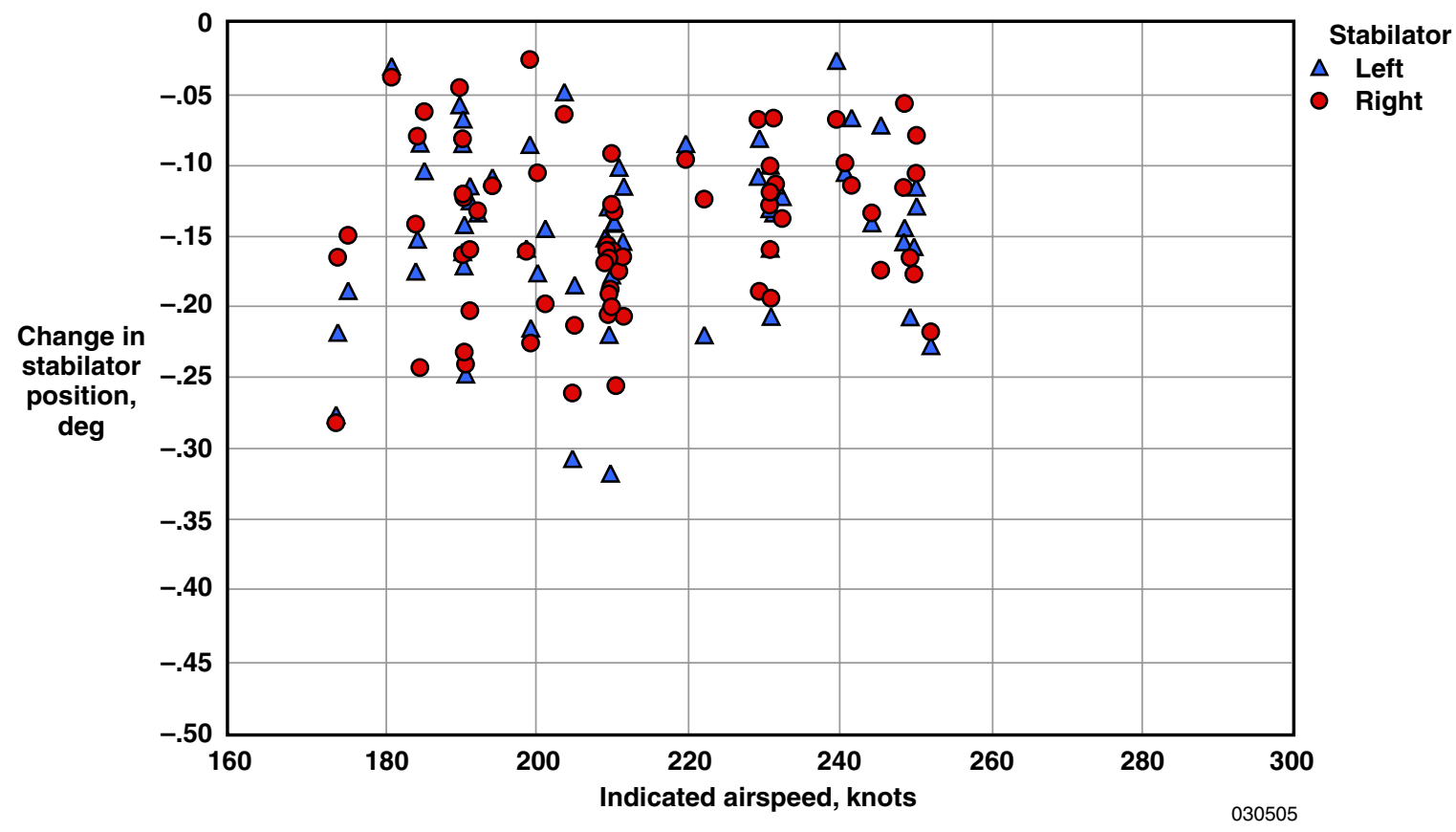

Figure 4. Change in F/A-18A horizontal stabilator trim positions with the paradrogue assembly extended. 


\section{FLIGHT TEST DESCRIPTION}

Phase 0 flight testing consisted of a series of envelope expansion test points for carriage and operational use of the ARS on a NASA F/A-18A airplane. Investigation of the operational envelope included paradrogue assembly deployments, retractions, and engagements by the receiver airplane at various airspeeds and altitudes. Phase 1 flight testing involved mapping the static and dynamic response of the paradrogue assembly to various influences of the forebody of the receiver airplane. A total of 30 test points dedicated to acquiring airplane performance data were conducted at the primary test altitude, $29,000 \mathrm{ft}, 19$ test points were obtained at 7,500 ft and 17 test points were flown at intermediate altitudes $(21,000$ to $25,000 \mathrm{ft})$. Mach numbers ranged from 0.30 to 0.67 .

\section{ANALYSIS PROCEDURES}

In a back-to-back approach, the total drag of the airplane configured with the paradrogue assembly in the stowed position was compared to the total drag of the airplane with the paradrogue assembly deployed. Test points were defined by flying approximately $10 \mathrm{sec}$ of unaccelerated flight for steady-state data, followed next by the paradrogue assembly extension or retraction, and completed with an additional $10 \mathrm{sec}$ of unaccelerated flight. Previous experience with the AFF project showed only $10 \mathrm{sec}$ of stabilized data was necessary to obtain adequate performance results. Using this flight test technique during the AFF and AAR projects, it often took several seconds or even minutes to set-up each test point and then achieve the desired stabilized conditions. The real-time drag display provided a direct indication that a stabilized drag value had been achieved. To achieve and maintain test conditions, each test point was flown with the barometric altitude hold and ATC engaged, giving the onboard computer a large degree of control for maintaining steady-state flight. As the paradrogue assembly is deployed, the drag of the vehicle increases and the engines must produce more thrust to maintain a constant airspeed. Measuring this change in thrust provides a good approximation of the change in airplane drag.

Performance data were determined using classical techniques. The wind-axis coordinate system was used as a frame of reference to calculate airplane lift and drag, with the flightpath angle assumed to be zero. Total airplane drag was calculated with the paradrogue assembly retracted and with it extended to determine the drag of the paradrogue assembly. Total lift was required for development of drag polars for tracking airplane performance. A summation of forces along the flightpath was used to determine airplane total drag and a force balance perpendicular to that drag was used to determine lift:

$$
\begin{gathered}
D=\cos (\alpha+\tau) F_{G}-F_{R A M}-F E_{D R A G}-(G W)\left(A_{X_{w}}\right) \\
L=(G W)\left(N_{Z_{w}}\right)-\sin (\alpha+\tau) F_{G}
\end{gathered}
$$

The IFT model of the engine manufacturer was used to calculate thrust for the engines installed in the tanker airplane. $^{6}$ The "Instrumentation" section of this report describes the measurements used in this model. The model calculated gross thrust $\left(F_{G}\right)$, ram drag $\left(F_{R A M}\right)$, and engine throttle-dependent drag, $\left(F E_{D R A G}\right)$. Gross thrust is the primary force the engine produces out the tailpipe, $F_{R A M}$ represents the force loss caused by the momentum of air entering the inlet, and $F E_{D R A G}$ accounts for the external drag forces associated with the engine nozzle and inlet spillage flow. The engine incidence angle $(\tau)$ accounts for the physical alignment of the nozzles not being directly along the body axis of the airplane. The IFT model also accounts for bleed-air and horsepower extraction specific to the F/A-18 airplane installation.

An airdata model provides Mach number, pressure altitude, and angle of attack $(\alpha)$. The model also computes gross weight $(G W)$ using empty weight, crew weight, and the remaining total fuel. The INS was used to obtain vehicle flightpath accelerations $\left(A_{X_{w}}\right.$ and $N_{Z_{w}}$ ). These data were corrected for rotation effects caused by the INS not being mounted exactly on the center of gravity. The INS provided body axis acceleration data that were translated into the flightpath (wind-axis) coordinate system. Flightpath acceleration $\left(A_{X_{w}}\right)$ and vehicle gross weight $(G W)$ were used to compute vehicle excess thrust as shown in equation (2). Vehicle total lift $(L)$ is closely related to the gross weight $(G W)$ shown in equation (3).

\section{RESULTS AND DISCUSSION}

The AAR project obtained definitive drag data for an aerial refueling system. Limited, if any, drag calculations have been obtained and reported for an aerial refueling system while in flight. Analysis of the flight data for stabilized extensions and retractions indicate the paradrogue assembly produced a drag value that ranged from $200 \mathrm{lbf}$ at $170 \mathrm{KIAS}$ to $450 \mathrm{lbf}$ at 250 KIAS (fig. 5). 


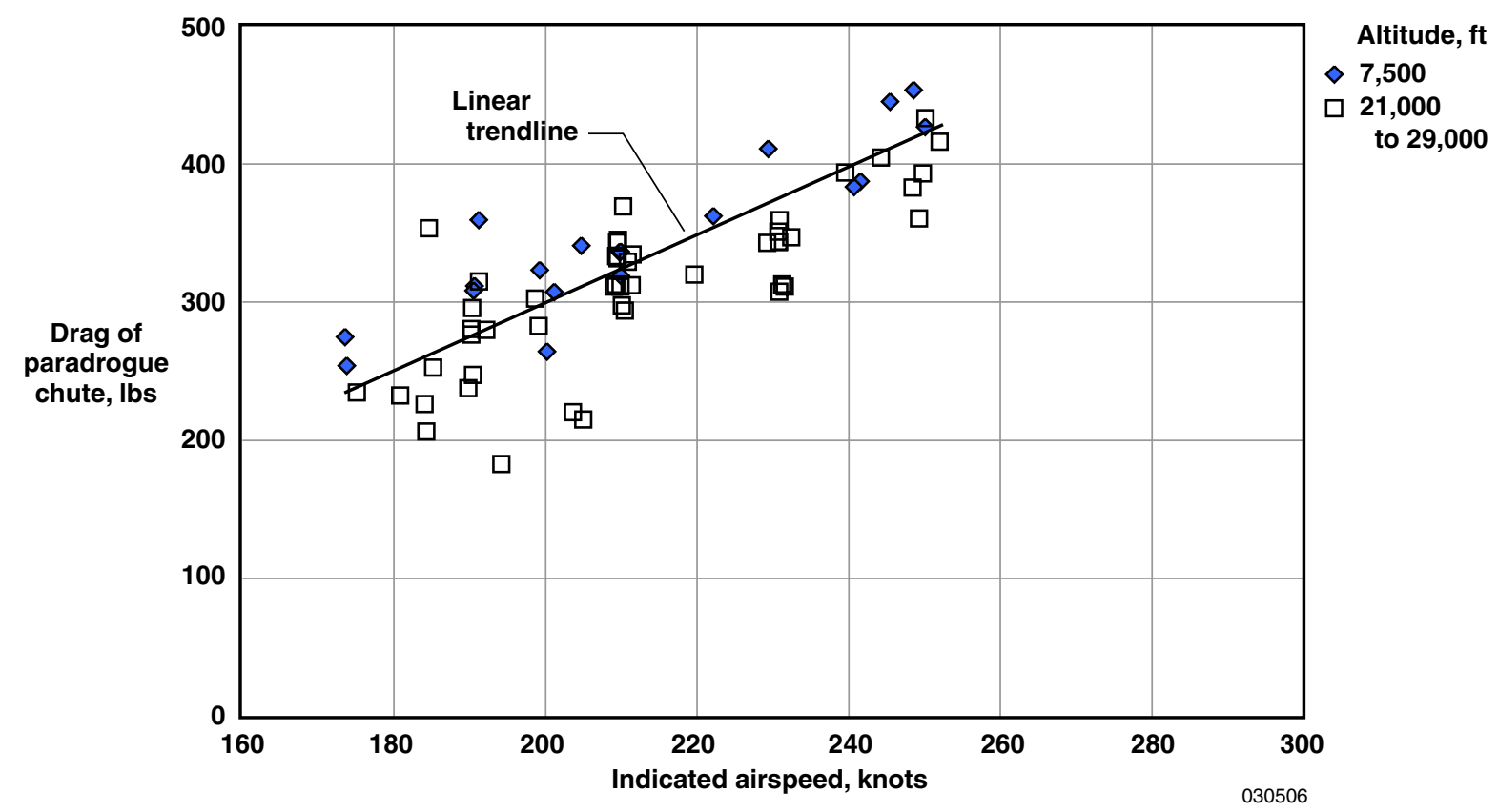

Figure 5. Summary of ARS paradrogue assembly drag during in-flight extensions and retractions.

Although there is a fair amount of scatter in the absolute drag data for the paradrogue assembly, clear trends with airspeed are shown for the two altitude ranges indicated. The prevailing trend in the drag data appears linear for the range of airspeeds tested. There is also no discernible altitude affect on the data. Drag data at all altitudes appear to follow the same general linear trend.

\section{Paradrogue Assembly Drag}

When the receiver airplane engaged the paradrogue assembly, some of the aerodynamic load (drag) generated by the paradrogue assembly was transferred from the tanker to the refueling probe of the receiver. This drag relief could be determined from tanker drag data, as illustrated in figure 6 , in which the drag change calculated for the tanker airplane is plotted for 55 engagements. Typically, up to $20 \mathrm{ft}$ of refueling hose is reeled in during these engagements, also contributing to the drag relief on the tanker airplane. The relieved load ranged from 35 to $270 \mathrm{lbf}$ at 170 and 250 KIAS, respectively. Note that figure 6 is plotted with the same ordinate and abscissa as figure 5. By comparing the two figures and accounting for scatter in the two data sets, there is anywhere from 150 to $250 \mathrm{lbf}$ of drag that remains on the tanker airplane when the receiver airplane engages the paradrogue assembly. Note also that there is a significant discrepancy in the consistency of the engagement data. For example, at 250 KIAS, the drag relief on the tanker airplane had a range of $180 \mathrm{lbf}$. This is primarily because of variations in pilot technique. After engaging the paradrogue assembly, each AAR pilot pushed the hose into the ARS at a range of comfortable distances. Both the length of hose still exposed outside of the ARS and the angle at which the receiver airplane holds the hose relative to the tanker airplane influence the calculated drag.

To assess the reasonableness of the engagement data, it was desirable to compare the flight results with simple prediction theory. The hose that connects the ARS pod to the paradrogue assembly constitutes a spring-massdamper system. This characteristic plays an important role during dynamic refueling maneuvers and in turbulence. For this paper, the hose will be treated as a fixed cylinder, simplifying aerodynamic analysis by removing the effect of curvature, bending, or flexure from the calculations. Data were only analyzed after the paradrogue assembly was fully deployed and stabilized (little or no hose dynamics were included). From Hoerner's text, ${ }^{10}$ the hose has a drag coefficient of approximately 0.20 . The assumed length of the hose when deployed is $47 \mathrm{ft}$, it has a diameter of 2.0 in., and trails the F/A-18A airplane at anywhere from 10 to $19 \mathrm{deg}$ below the ARS centerline, depending on dynamic pressure. This range of trailing angles result in estimated hose drag of roughly 60 to $100 \mathrm{lbf}$, depending on flight condition. Such an estimate does not fully account for the remaining drag on the tanker as the receiver engages the paradrogue assembly (fig. 6). 


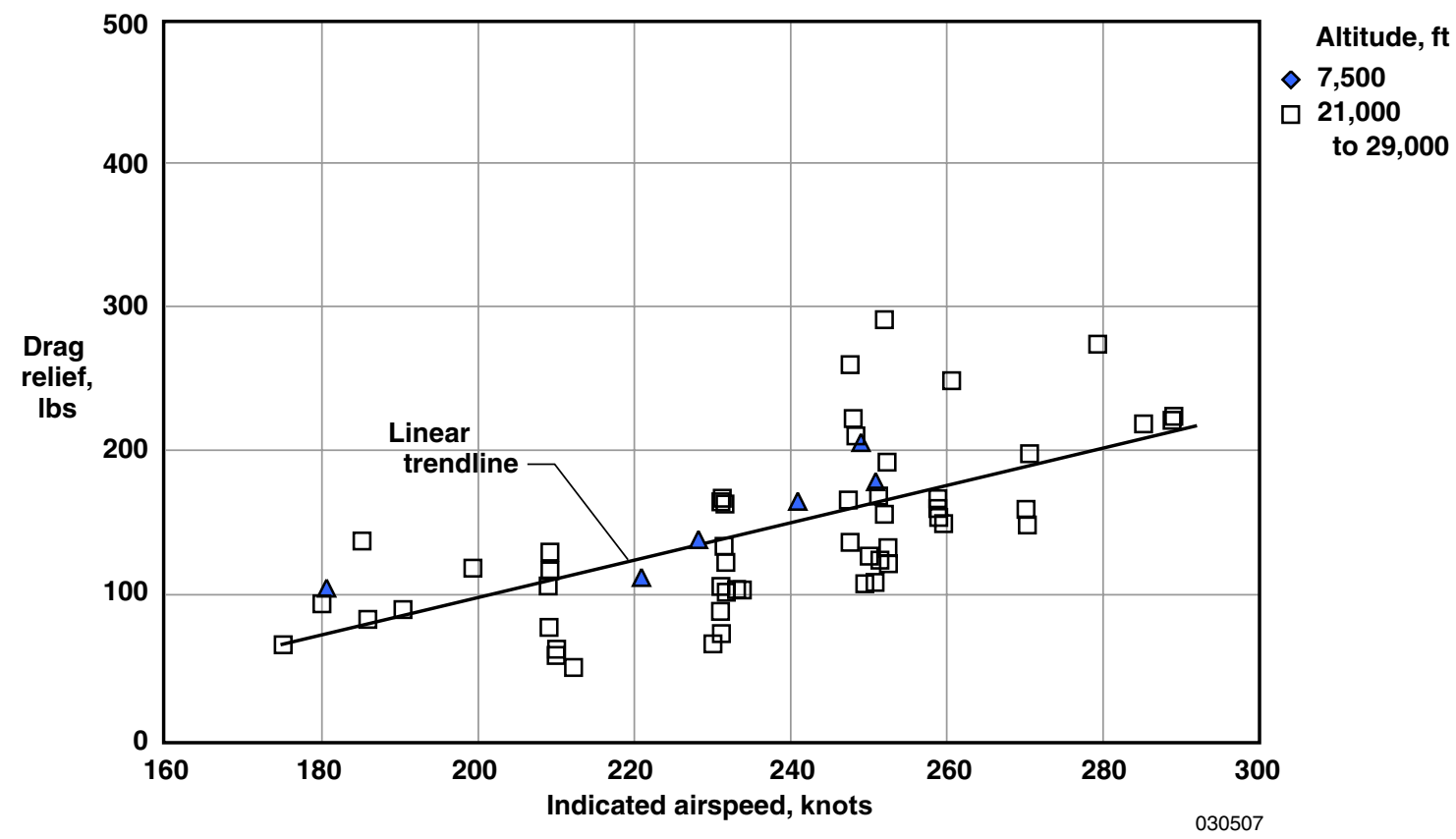

Figure 6. Calculated drag relief on the tanker airplane when the paradrogue assembly is engaged by the receiving airplane.

So some additional drag sources have not been accounted for in the estimation. In particular, interference drag, which is difficult to estimate, can also make significant contributions to the drag of the paradrogue assembly. There is also the possibility that the flowfields around both the tanker and receiver airplanes could be interacting during these close-in engagements, further affecting the drag results.

\section{Comparison with Wind Tunnel Results}

The AAR project was supplied with an older, high-drag paradrogue canopy for testing. This paradrogue is identified as a "-18" paradrogue assembly. The Navy has recently developed a low-drag paradrogue canopy for use with the F/A-18 E/F Super Hornet. This new paradrogue assembly has been given the label "F-18," not to be confused with the airplane on which it flies. Because of its lower drag, the newer paradrogue assembly trails lower behind the tanker airplane when deployed (a highly desirable improvement). Wind tunnel testing at 175 knots on one-sixth conical sections of the older and newer paradrogue assemblies was completed by NAVAIR. Figure 7 shows the NAVAIR wind tunnel test setup. The data were used to extrapolate drag predictions for the paradrogue assemblies at a constant drag coefficient to airspeeds up to 300 knots. This airspeed range was chosen because it coincides with the minimum and maximum allowable airspeeds for which the paradrogue assembly is deployed in Naval operations. The wind tunnel results for the paradrogue assemblies were added to empirical drag estimates of the installation with the hose and coupling. The resulting Navy-derived predictions (and associated wind tunnel anchor points) are plotted in figure 8 as two parabolic curves. The upper curve represents the drag estimate for the high-drag, "-18," paradrogue assembly, and the lower curve corresponds to the low-drag, "F-18," paradrogue assembly. These linear estimates are then compared with the NASA AAR data at all airspeeds tested in flight as shown. 


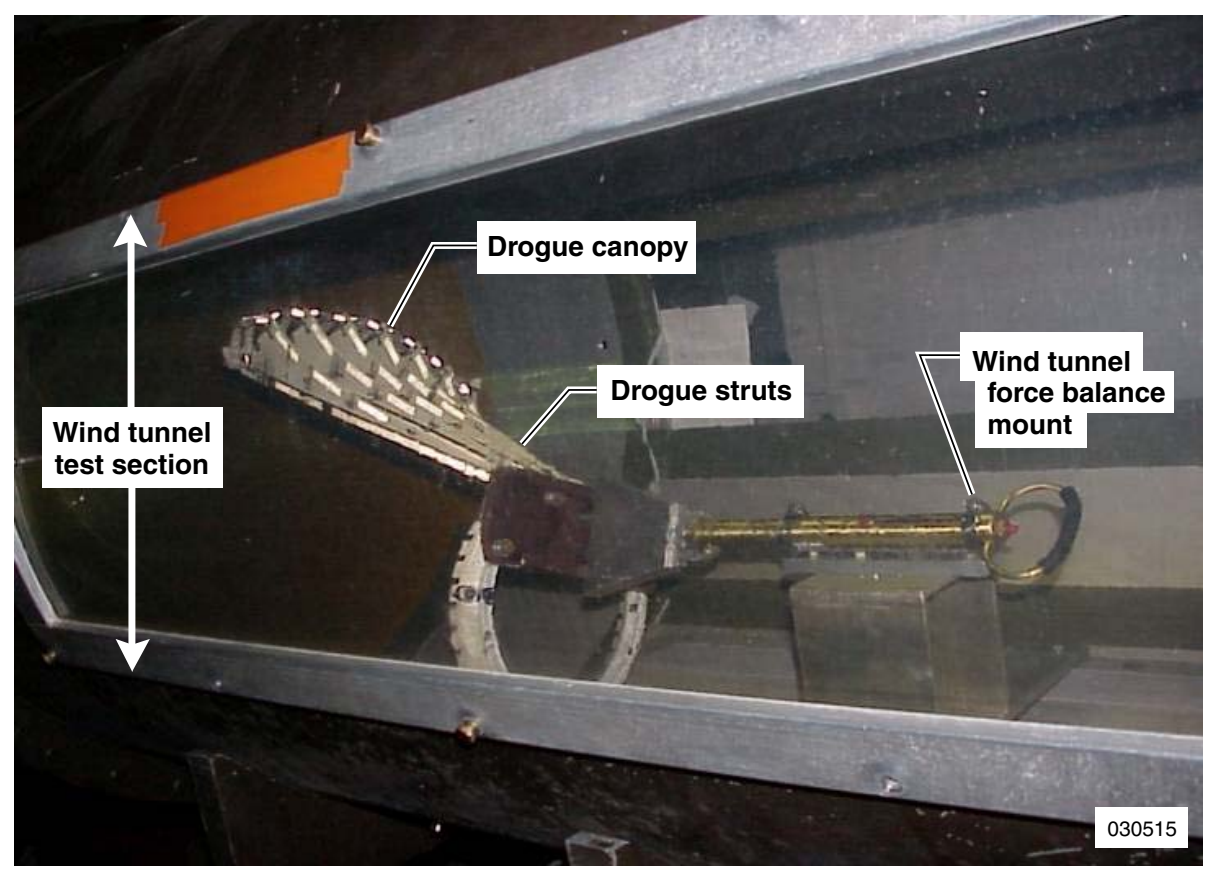

Figure 7. Navy wind tunnel test setup (courtesy of Carl Calianno, NAVAIR).

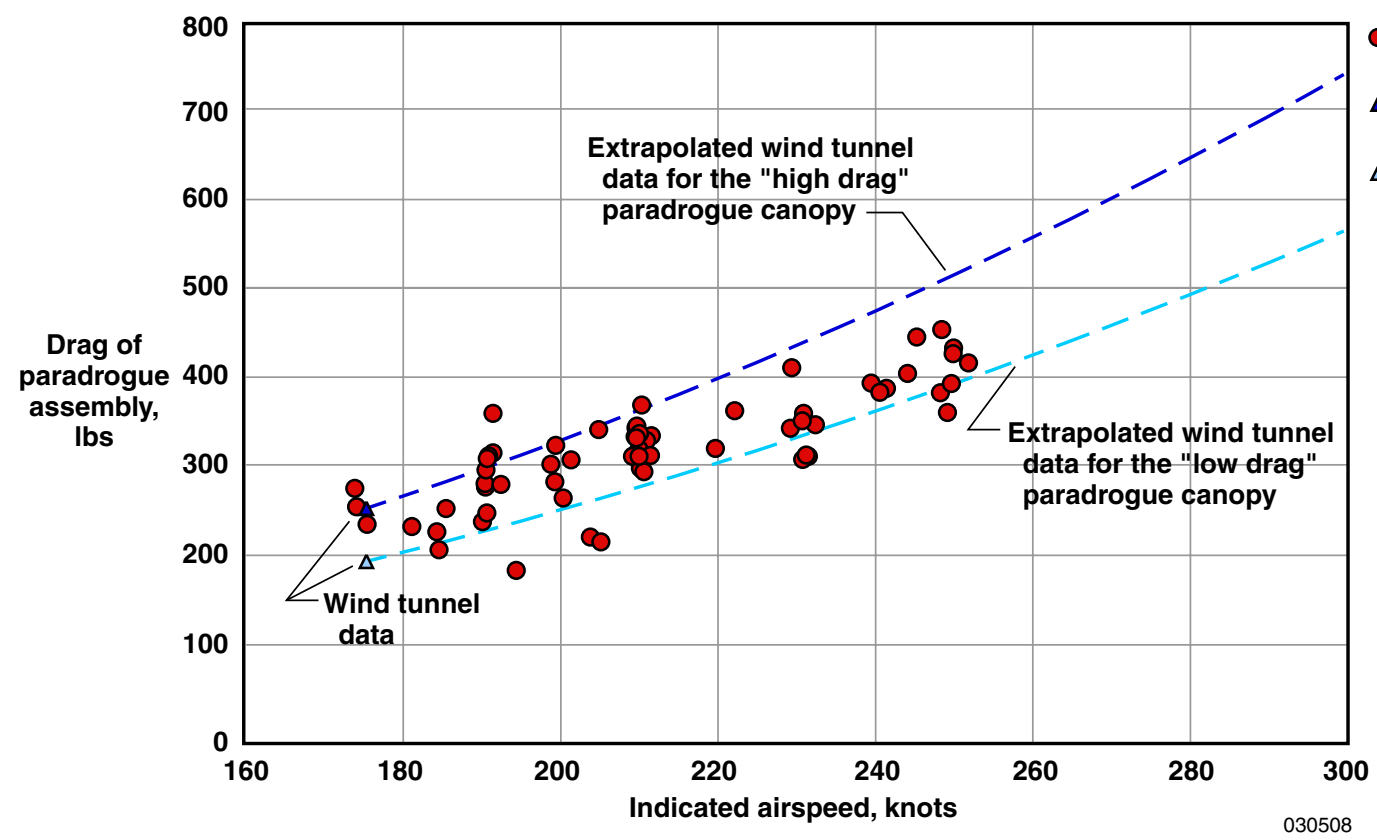

- NASA '-18'

flight data

$\Delta$ Navy '-18' wind

tunnel data

$\Delta$ Navy 'F-18' wind

tunnel data

Figure 8. Comparison of AAR paradrogue drag data to Navy wind tunnel results. 
Figure 8 shows most of the flight test results are bounded by the extrapolated wind tunnel data. This correlation adds confidence to the flight data. At 175 knots, the flight data correspond very well with the wind tunnel test point for the "-18" paradrogue assembly. However, over the full airspeed envelope, the flight data for the "-18" paradrogue assembly suggest that the paradrogue generates a lower drag than what had been predicted by the wind tunnel tests, with several higher-drag exceptions. At higher airspeeds, the flight data appears closer to the predicted drag values for the "F-18" paradrogue assembly. Figure 9 shows the flight data were generally 0 to 20 percent lower than the wind tunnel predictions for the "-18" paradrogue assembly.

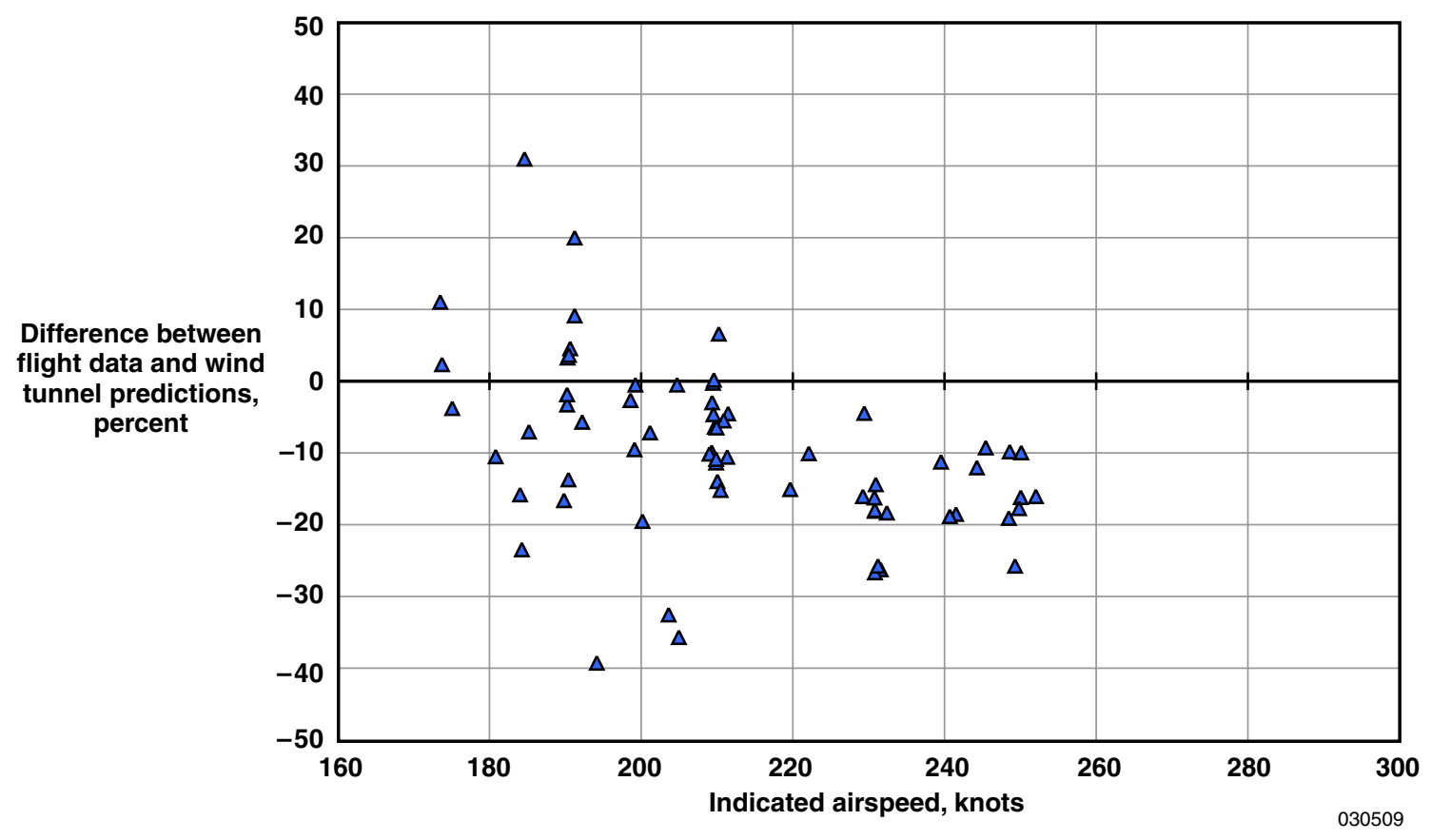

Figure 9. Difference in paradrogue drag between NASA flight data and Navy predictions for the "-18" paradrogue canopy. 
Effect of Paradrogue Assembly on F/A-18A Airplane Lift

Figures 10(a) and 10(b) show there is no discernable change in airplane lift as a function of deploying the paradrogue assembly. The lift coefficient appears to remain constant as the paradrogue assembly is extended and retracted. Within the accuracy limits of the flight test technique, the calculated lift overlaps at each test point for paradrogue assembly extension and retraction.
For comparison, data from the AFF project are also plotted on figure 10(a), and these points lie on the upper side of the lift curve data set. This comparison adds confidence to the current results. Although the airplane configuration has changed in wetted area and weight since the AFF project flew (the AFF configuration carried no external stores or pylons), the airplane still performed along the same lift curve.

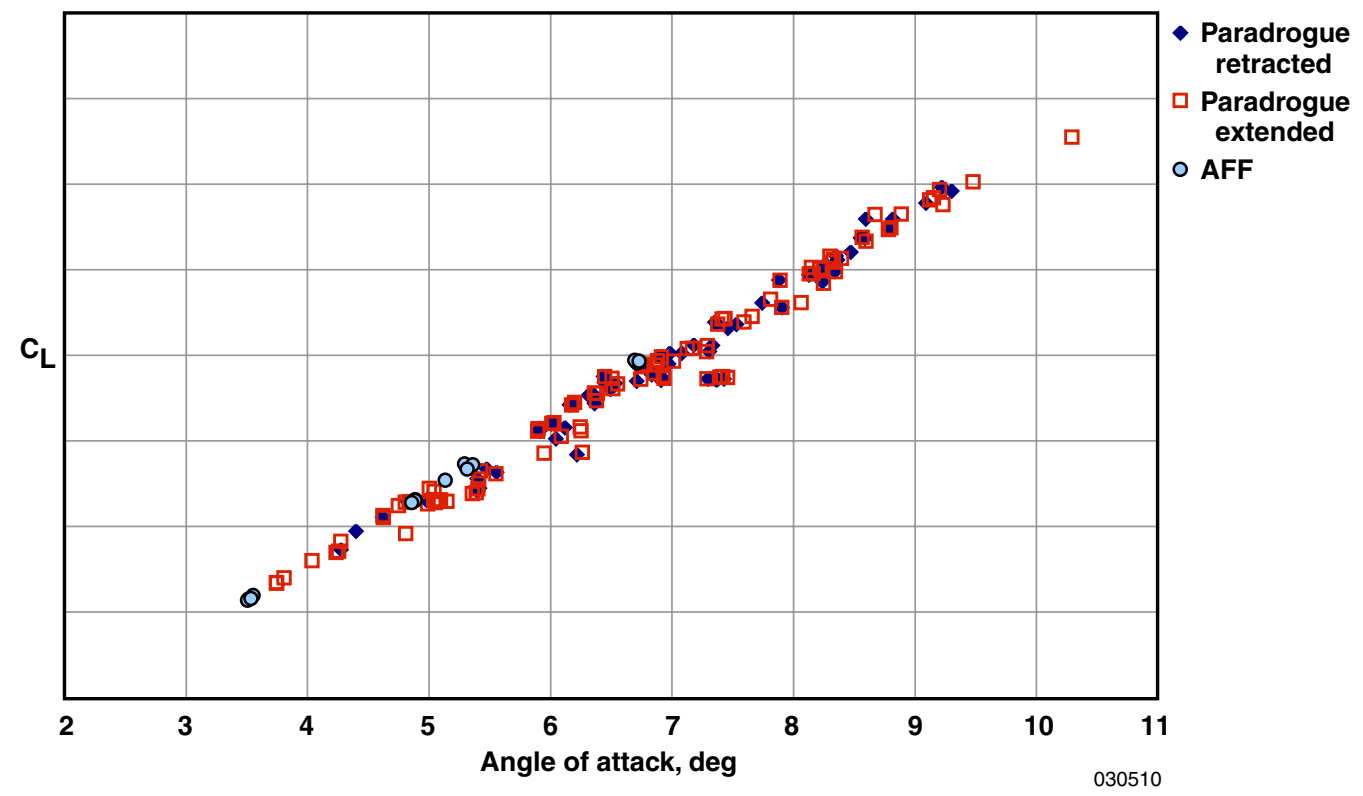

(a) Flight-determined airplane lift coefficient as a function of angle of attack.

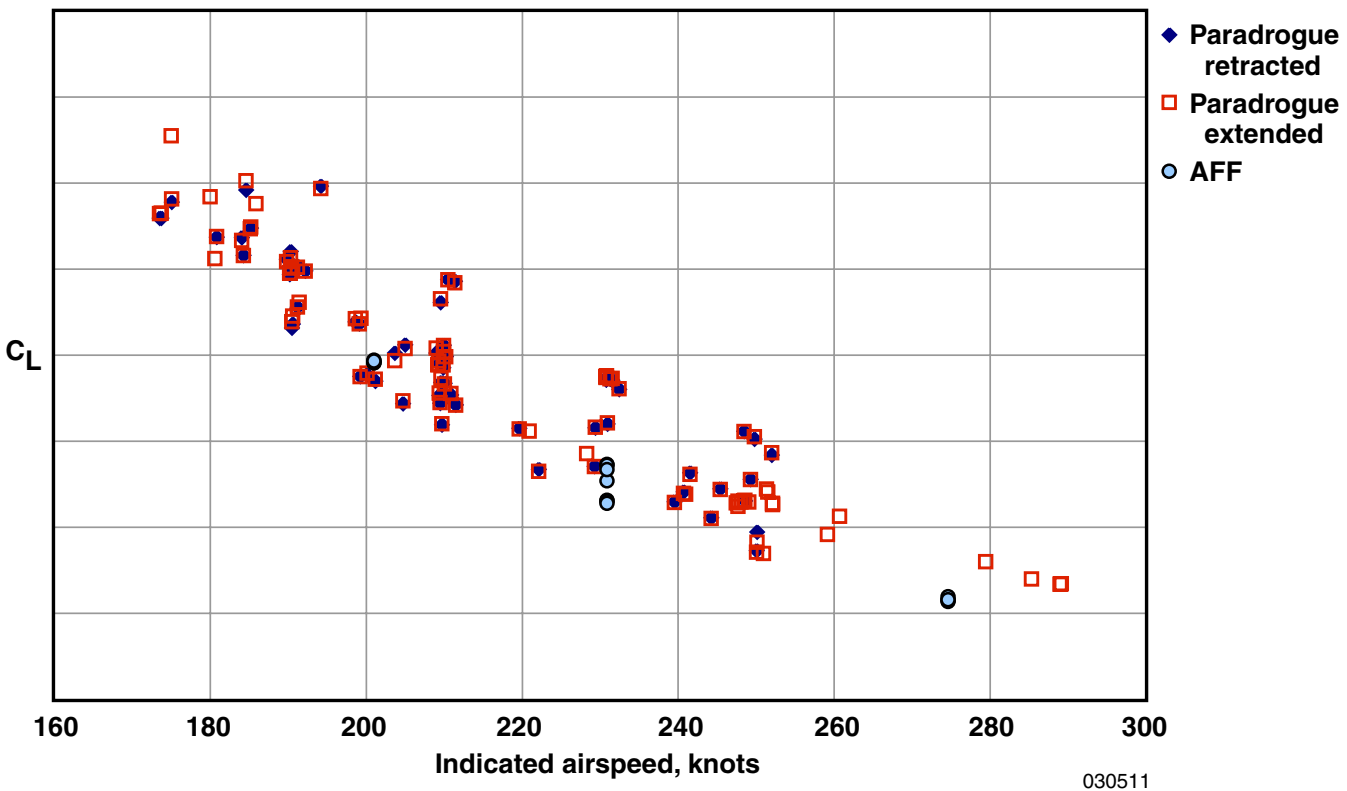

(b) Flight-determined airplane lift coefficient as a function of airspeed.

Figure 10. Flight-determined airplane lift coefficient, $C_{L}$. 


\section{Drag Coefficient of Paradrogue Assembly}

It was desirable to improve current and future AAR simulations by adding in the drag of the refueling system to the aerodynamic model. To simplify this process, it was desirable to find a singular, consistent drag coefficient for the paradrogue assembly and apply that single drag coefficient to the simulation for all airspeeds. By plotting the airplane total drag coefficient versus airspeed for all test points, figure 11 shows two distinct sets of data appear, separated by a relatively constant offset. These data sets represent the drag coefficient for the F/A-18A airplane with the paradrogue assembly both retracted and then deployed behind the airplane. Plotting second-order trendlines through these two data sets provide clearly identifiable drag curves for the airplane in each configuration; but more importantly, they highlight the relatively constant offset between the two sets of data. The constant offset between the curves, attributable to the paradrogue assembly, lends confidence to the flight data and postflight analysis technique. The drag coefficient of the paradrogue assembly is plotted as a separate data set at the bottom of figure 11, and it represents the difference between the two primary curves. Plotting a linear trendline through this data provides a good first-order equation for the drag of the paradrogue assembly, with an average value of 0.0056 . Changes in airplane velocity have little affect on the drag coefficient of the paradrogue assembly, supporting the use of a constant value for all conditions. Also plotted on figure 11 are data from the AFF project. ${ }^{4}$ The AFF configuration has a lower drag and appears just below the AAR paradrogue assembly retracted curve. This lower drag is expected because the AFF project did not utilize external stores or pylons (reducing profile drag) and was lighter in weight (reducing induced drag).

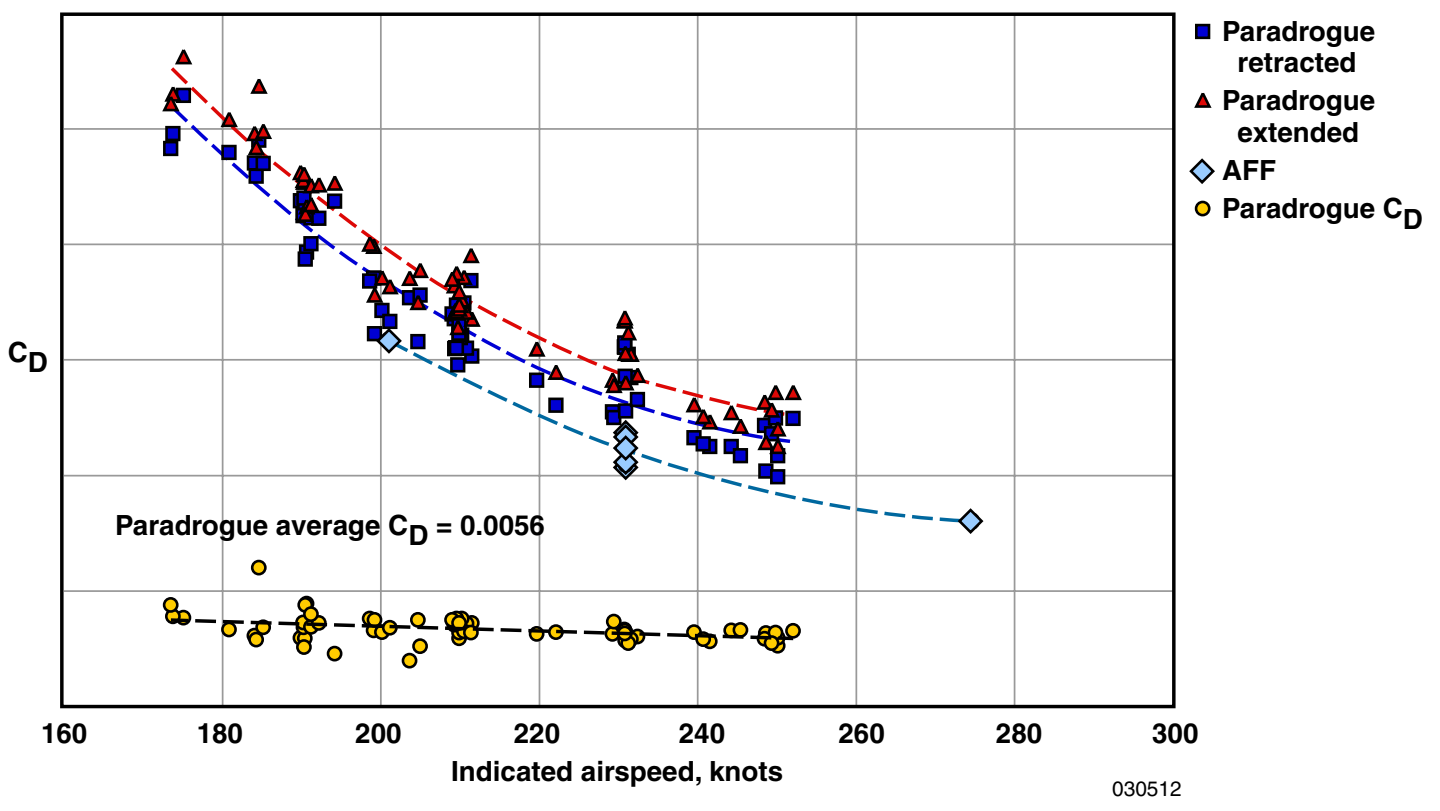

Figure 11. Flight-determined total airplane drag coefficient as a function of airspeed, showing the consistent value for the paradrogue assembly drag coefficient. 
Paradrogue Assembly Drag through F/A-18A Airplane Drag Polar Analysis

Figure 12 presents two drag polars for the F/A-18A airplane, and these curves were derived from all the test points investigated during AAR Phases 0 and 1. This figure provides data similar to figure 11, but encompasses all steady-state test points, regardless of whether the paradrogue assembly was actively deployed or retracted during the particular test point. It is interesting to evaluate the drag polar data, as it is comprised of the individual absolute performance numbers for each test point.

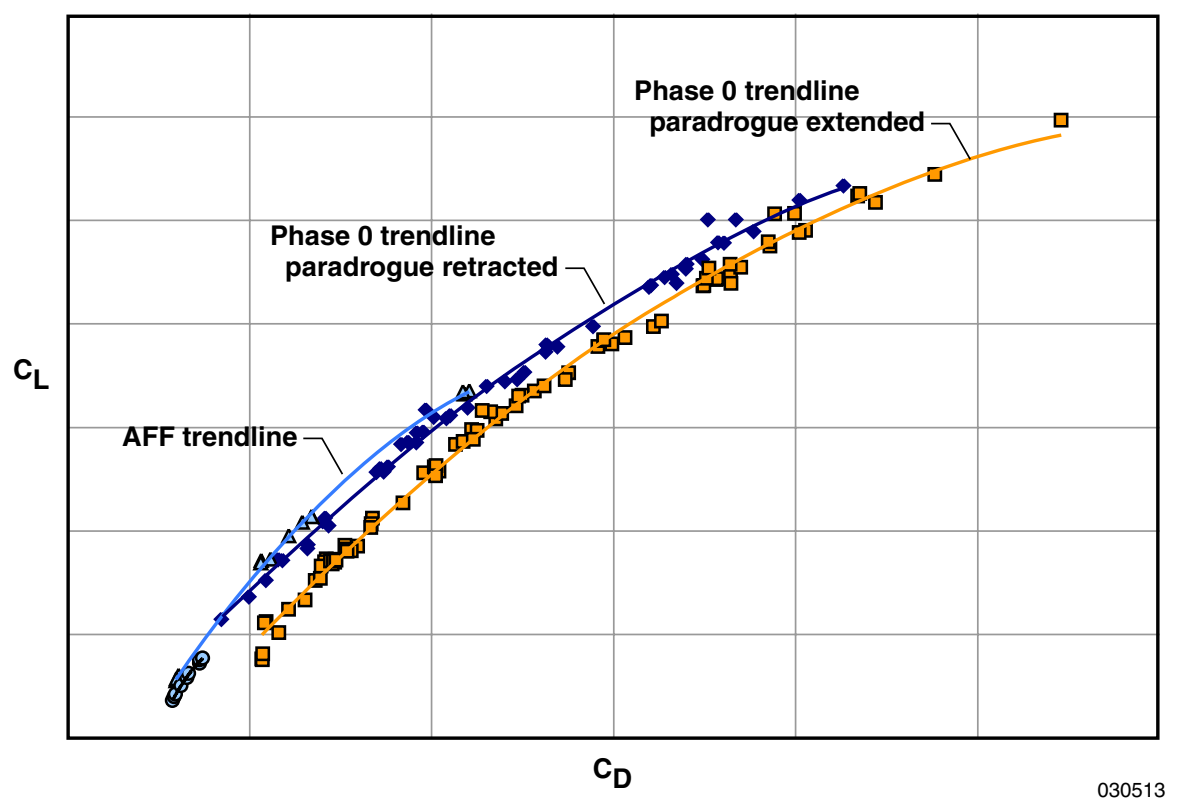

- Paradrogue retracted (AAR Phase 0)

口 Paradrogue extended (AAR Phase 0)

$\triangle \quad$ AFF Mach number $=0.44-0.66$

○ AFF Mach number $=0.86$

(a) AAR Phase 0 drag polars.

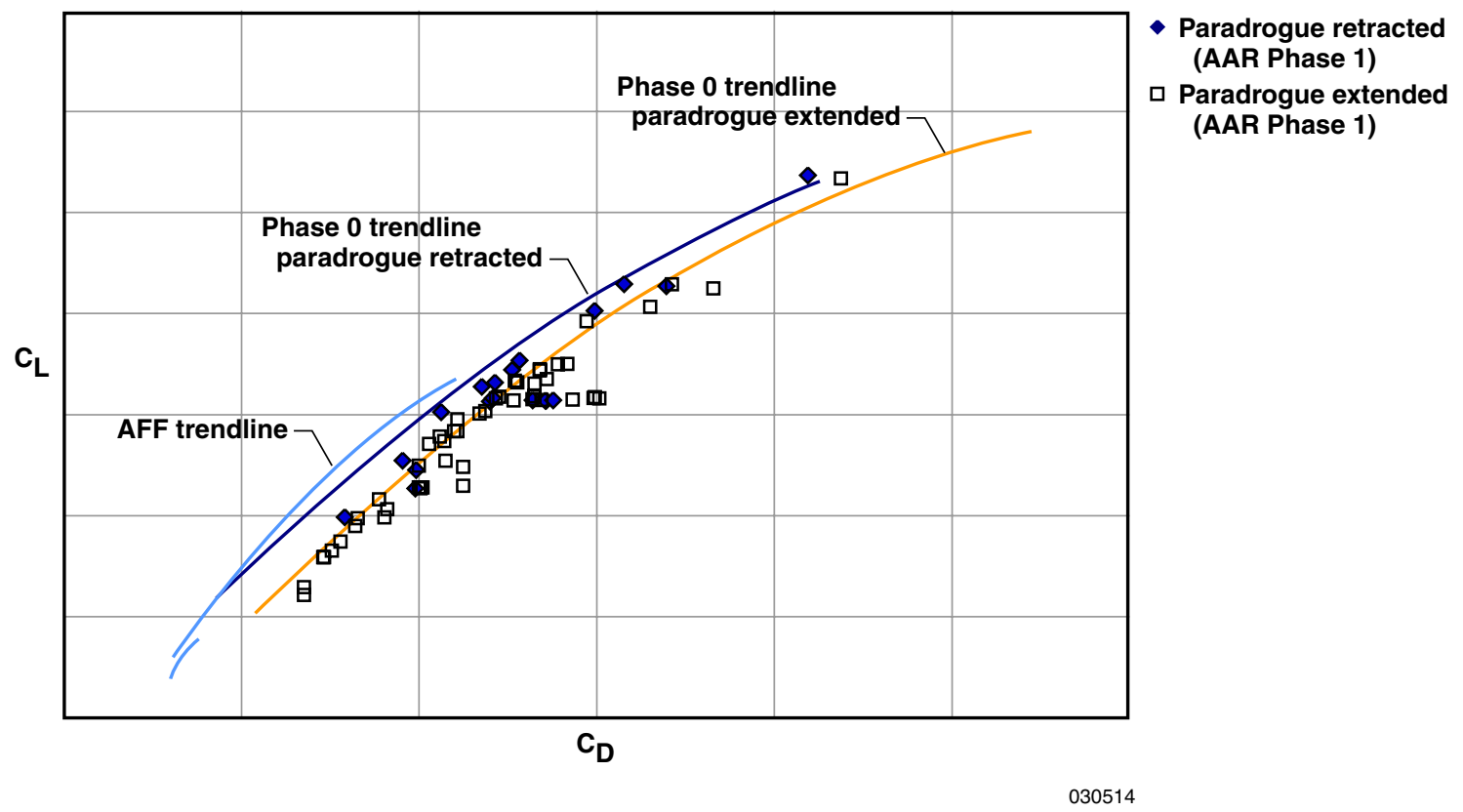

(b) AAR Phase 1 drag polars, compared with Phase 0 trendlines.

Figure 12. F/A-18A airplane drag polars for the Automated Aerial Refueling and Autonomous Formation Flight projects. 
Figure 12(a) contains data exclusively from Phase 0 , when dedicated performance test points were flown at tightly controlled flight conditions. Figure 12(b) contains data points from Phase 1, during which performance data could only be gleaned from the steady-state start or end of test points that were focused primarily on mapping the response of the paradrogue assembly to influences of the receiver airplane. Trendlines through the data of figure 12(a) clearly show two drag polars were obtained for the paradrogue assembly, one retracted and one extended. This data complements the results shown in figures 5 and 8 where the back-to-back analysis only summarizes the change in drag while the paradrogue assembly was extended or retracted. The constant offset in the data is clearly evident when comparing the drag polar trendlines and has a magnitude between 0.005 and 0.007 , adding confidence to the estimated singular drag coefficient for the paradrogue assembly of 0.0056 . This data can also be compared with the drag polar for the same F/A-18A airplane during the AFF project flights. The AFF data at high- and low-speed flight conditions agree with the AAR data with the paradrogue assembly stowed, yet shows slightly less drag, as expected.

For comparison purposes, figure 12(b) contains the trendlines from figure 12(a). For the Phase 1 data, there is an apparent shift to the right of the airplane drag polar with the paradrogue assembly retracted. This is an expected result, with the addition of two external wing tanks contributing to an increased-drag configuration. This trend matches that first shown in figure 12(a), as the AAR Phase 0 configuration shifted in a similar manner to the right of AFF data. However, additional data points must be gathered for this configuration with the paradrogue assembly retracted to reach definitive conclusions. Data forming the drag polar with the paradrogue assembly extended match the trendline developed in figure 12(a). Accounting for scatter in the flight data, the data set for the paradrogue assembly extended does not make any apparent shift to the right. Data for the two different AAR configurations (Phase 0, one external store; Phase 1, three external stores) agree well with one another, though there is noticeably more scatter in the Phase 1 data.

\section{CONCLUSIONS}

With specific engine thrust-measurement instrumentation installed in the tanker airplane, the Automated Aerial Refueling project was able to accurately determine the drag of an aerial refueling paradrogue assembly in flight. For stabilized extensions and retractions of the paradrogue assembly, the drag of the tanker airplane changed by a minimum of $200 \mathrm{lbf}$ at $170 \mathrm{KIAS}$ and a maximum of $450 \mathrm{lbf}$ at $250 \mathrm{KIAS}$. The drag results are 0 to 20 percent lower than what was predicted for this paradrogue assembly through Navy wind tunnel testing, and appear to be independent of altitude. Trim drag changes were analyzed and found to have negligible affects on the ARS performance results. Analyses of the flight results indicate a good first-order approximation of the drag coefficient for the "-18" (high-drag) paradrogue assembly is a constant value of 0.0056 for all flight conditions tested. When the receiver airplane engaged the paradrogue assembly, the aerodynamic drag load on the tanker airplane was relieved by 35 to $270 \mathrm{lbf}$ at 170 and 250 KIAS, respectively. Lift and drag data for the tanker airplane with the paradrogue assembly stowed compares favorably with data from the AFF flight tests with a clean F/A-18A airplane configuration. Comparison of the drag polar results for the paradrogue assembly, both extended and retracted, clearly shows a constant increase in drag coefficient when the paradrogue assembly is extended. Data from the paradrogue assembly drag analysis improves the AAR simulation, future Navy and Air Force aerial refueling system development programs, and the predictability of integrated manned and unmanned refueling operations.

\section{REFERENCES}

${ }^{1}$ Rumerman, Judy, "Alexander de Seversky and Seversky Aircraft." U.S. Centennial of Flight Commission. http://www.centennialofflight.gov/essay/ Aerospace/Seversky/Aero42.htm Accessed October 17, 2003.

${ }^{2}$ Smith, Richard K., Seventy-Five Years of Inflight Refueling, Highlights 1923 to 1998. Air Force History and Museums Program, Washington, D.C., 1998. http://www.airforcehistory.hq.af.mil/Publications/fulltext/ 75yrs inflight refueling.pdf Accessed October 17, 2003.

3“KC-10 Extender." U.S. Air Force Fact Sheet, Air Force Link, Library, Fact Sheets, October 2003. http://www.af.mil/factsheets/factsheet.asp?fsID=109

Accessed October 17, 2003.

${ }^{4}$ Ray, Ronald J., Brent R. Cobleigh, M. Jake Vachon, and Clinton St. John, Flight Test Techniques Used to Evaluate Performance Benefits During Formation Flight, NASA/TP-2002-210730, 2002.

${ }^{5}$ Bever, Glenn, Peter Urschel, and Curtis E. Hanson, Comparison of Relative Navigation Solutions Applied Between Two Aircraft, NASA TM-2002-210728, 2002. 
${ }^{6}$ General Electric Company, "F404-GE-400 Engine In-Flight Thrust Calculation Program," software program no. 83112, version 8-08-83, General Electric Company, Lynn, Massachusetts, 1983.

${ }^{7}$ Ray, Ronald J., Evaluation of Various Thrust Calculation Techniques on an F404 Engine, NASA TP-3001, 1990.

${ }^{8}$ Conners, Timothy R., Measurement Effects on the Calculation of In-Flight Thrust for an F404 Turbofan Engine, NASA TM-4140, 1989.

${ }^{9}$ Ray, R. J., J. W. Hicks, and R. I. Alexander, Development of a Real-Time Aeroperformance Analysis Technique for the X-29A Advanced Technology Demonstrator, NASA TM-100432, 1988.

${ }^{10}$ Hoerner, Sighard F., Fluid-Dynamic Drag: Practical Information on Aerodynamic Drag and Hydrodynamic Resistance, Self-published work, Library of Congress Catalog Card Number 64-19666, Washington, D.C., 1965. 


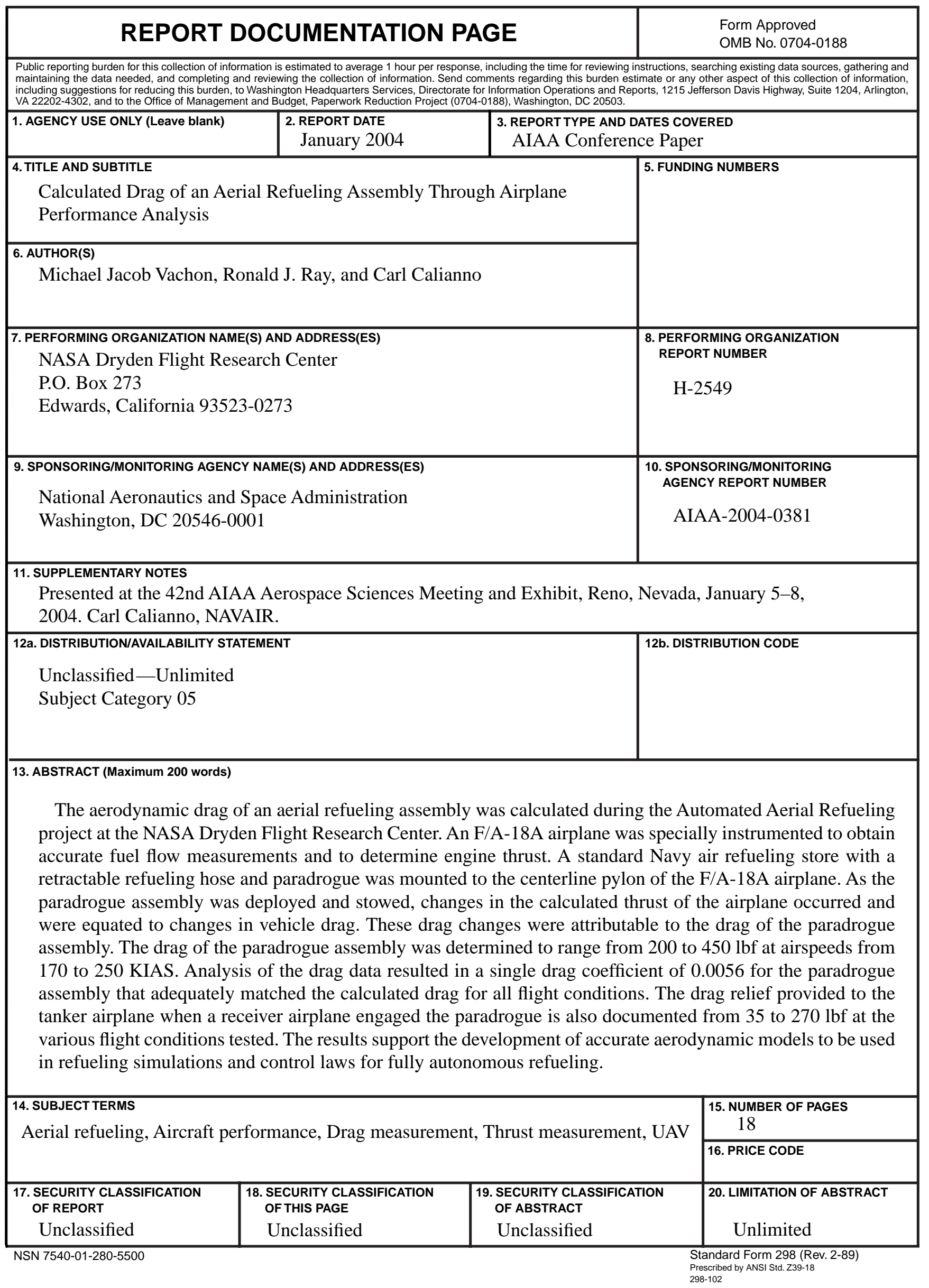

